\title{
Specificities and Peculiarities in Determining the Nature of the Concept "Small and Medium-Sized Enterprises"
}

\author{
$\mathrm{PhD}$ candidate Hristina Vasileva \\ University of Economics - Varna, Varna, Bulgaria \\ hristinagvasileva@ue-varna.bg
}

\begin{abstract}
SMEs are one of the most widely used business models in today's economy. This explains the great scientific and applied interest in them as one of the elements in the economic system that is subject to constant study. For the purposes of SME management, the essence of this concept needs to be clearly defined. There are two approaches to defining it, quantitative and qualitative. In the specialist literature, each of approaches has both advantages and disadvantages. The present study provides a critical analysis of existing approaches, on the basis of which a new comprehensive approach is proposed to define the concept of SMEs
\end{abstract}

Keywords: SME definition, qualitative and quantitative characteristics

JEL Code: L11; doi:10.36997/IJUSV-ESS/2019.8.1.75

\section{Въведение}

Актуалните параметри на пазарната конюнктура и измеренията на конкуренцията налагат като успешен бизнес формат малките и средни предприятия (МСП), което се доказва и от техния относителен дял в състава на всички предприятия, действащи в границите на Европейския съюз. По данни публикувани на 20 ноември 2018 година в годишния доклад за малките и средни предприятия в Европейския съюз те представляват 99\% от всички предприятия и осигуряват $66 \%$ от общата заетост в частния сектор на съюза. На тази основа МСП се определят като гръбнак на европейската икономика ( Annual Report on European SMEs2017/2018,EC,https://ec.europa.eu/growth/smes/business-friendly-environment/performancereview_en). Любчо Варимезов в своята монография „Малките предприятия в съвременната икономика“(Варимезов, 2000) определя нарастващият брой и повишаването на социалноикономическото значение на малките предприятия, като едно от най-забележителните явления в световната икономика и тенденция, която впечатлява със своята устойчивост.

В специализираната литература се срещат множество дефиниции за малките и средните предприятия. Статистическите агенции, международните организации, правителствата на отделните държави използват различни определения. Въпреки голямото значение на МСП за световната икономика все още няма уникално и универсално прието определение за малките и средни предприятия. Текущите критерии са претърпели преразглеждане, но към момента няма сближаване по отношение на определенията, дори при международните организации, които имат за членове едни и същи държави. Разнообразието на характеристиките и икономическите условия са фактори, които възпрепятстват съществуването на общоприето определение за МСП.

При дефинирането на МСП в специализираната литература се използват два подхода:

1. Дефиниции основани на количествени критерии;

2. Дефиниции основани на качествени характеристики.

При част от приетите определения се прилагат и двата подхода.

Целта на автора в настоящата разработка е на основата на анализ на предимствата и недостатъците на съществуващите подходи за дефиниране на понятието МСП, да предложи алтернативен подход, който до голяма степен елиминира недостатьците на съществуващите такива и може да бъде универсално приложим в съвременната икономика. Постигането на така поставената цел е свързано с решаване на две основни изследователски задачи, а именно: представяне на двата съществуващи подхода, използвани при дефинирането на 
МСП; и извършване на критичен анализ, извеждащ предимствата и недостатъците на тези два подхода.

\section{1. Количествени критерии при дефиниране на МСП}

Научните среди, политиците, международните институции и статистическите агенции прилагат главно количествени критерии при определянето на МСП. При дефиниране на МСП се използват най-вече количествените показатели, като броя на служителите и финансови критерии за годишния оборот, активите във финансовите отчети или сумата на баланса.

Количествените критерии осигуряват лесна категоризация на бизнеса, но често са критикувани, поради трудния достъп до данни. Авторът се присъединява към мнението на част от работещите по темата, че количествените характеристики не са по-обективни за определянето, но са по-лесни за идентифициране, от страна на публичните администрации от една страна и от икономическата статистика от друга страна. Размерът на отделните критерии, зависят от икономическото развитие на съответната държава, както и от социалните условия в нея.

Най-често прилаганият критерий за разграничаване между големите и малките предприятия е броят на служителите. Основната причина за този факт е прагматизма. Вероятен отговор на въпроса, защо тази характеристика е най-често използваната ни дава Филион (Filion,1990) - защото тази величина се публикува и лесно може да се контролира. Също така броя на заетите не зависи в такава степен от инфлацията като оборота на компаниите. В свое изследване Maria Madalina Buculescu (Buculescu,2013) представя и две мнения на автори, които са против използването на броя на заетите лица като основна характеристика. Тези автори считат, че броя на заетите не представят истинската картина на малките предприятия (Osteryoung,Newman,1993) и може неправилно да се предположи, че ако компанията е по-голяма се нуждае от повече заети лица, и за да се развива е необходимо да наеме повече лица, което може да доведе до заблуждаващата идея за неефективност на МСП (Gibson, Van der Vaart, 2008) Пак според тях оборота е по-реалистичен и значим показател, поради факта, че е налична информация за него и лесно може да се екстраполира.

Но дори и най-често използваният критерий в дефиницията, броят на служителите има много различия при различните източници на статистическо отчитане на МСП. Найголям брой източници определят МСП да имат гранична граница от 0-250 служители (Ayyagari et al,2007) Изследване на Световната банка, направено чрез публикация, известна като MSMB Country Indicators, показва, че от 132 страни, включени в проучването, 46 от тях, или една трета определят МСП като предприятия с по-малко от 250 служители (Kushnir et al, 2010). В повечето страни 250 души е делителя между голямо предприятие и сектора на МСП, като варира в широки граници от 10 в Индия, до 500 в САЩ. В развиващите се страни броя на работниците е значително по-мальк и обикновено компании с над 100 души се считат за големи. В редица проучвания 50 \% от предприятията в страните с нисък среден доход имат по-малко от 100 служители (Beck \& Cull, 2014; Dalberg, 2011).

Всяка страна упражнява свободата да определя МСП конкретно, факт който се потвърждава с множеството дефиниции. Таблица 1 представя някои от тях.

Европейската комисия насърчава "критерия за броя на служителите като основен критерий, но въвеждането на финансов критерий е необходим допълнителен елемент за разбиране на реалния мащаб и производителността на предприятието и неговата позиция в сравнение с неговите конкуренти" (Европейска комисия: 2003, т. 4).

Съгласно действащата дефиниция в рамките на ЕC за определяне на МСП приложимите критерии са: брой служители, годишен оборот и сума на годишния баланс (Европейска комисия: 2005 г.). Съответствието на критериите за броя на служителите е задължително, докато другите два критерия са допьлващи. Дефиницията за МСП, влязла в 
сила от 1 януари 2005 г., е показана в Таблица 2.

Таблица 1. Дефиниция на малките и средни предприятия в различни страни

\begin{tabular}{|l|c|c|c|c|c|}
\hline & Микро & Малко & Средно & МСП & Големи \\
\hline $\begin{array}{l}\text { Страни от ЕС, } \\
\text { Норвегия, Исландия } \\
\text { и Швейцария }\end{array}$ & $1-9$ & $10-49$ & $50-249$ & $1-249$ & $250+$ \\
\hline Австралия & $0-9$ & $10-49$ & $50-199$ & $0-199$ & $200+$ \\
\hline Канада & $0-9$ & $10-49$ & $50-499$ & $0-499$ & $500+$ \\
\hline Япония & $4-9$ & $10-49$ & $50-249$ & $1-249$ & $250+$ \\
\hline Корея & $5-9$ & $10-49$ & $50-199$ & $5-199$ & $200+$ \\
\hline Мексико & $0-10$ & $10-49$ & $51-250$ & $1-250$ & $251+$ \\
\hline Нова Зенландия & $1-9$ & $10-49$ & $50-99$ & $0-99$ & $100+$ \\
\hline Турция & $1-19$ & $10-49$ & $50-249$ & $1-249$ & $250+$ \\
\hline САЩ & $1-9$ & $10-99$ & $100-499$ & $1-499$ & $500+$ \\
\hline
\end{tabular}

Източник: ОИСР (2010 г.)

Таблица 2. Дефиниция на малките и средни предприятия сьгласно определенията на Европейския Съюз

\begin{tabular}{|l|c|c|c|}
\hline Категория предприятие & $\begin{array}{c}\text { Средно списъчен } \\
\text { брой на персонала }\end{array}$ & Годишен оборот & $\begin{array}{c}\text { Сума на } \\
\text { баланса }\end{array}$ \\
\hline Микро предприятие & $<10$ & $<=2$ млн.евро & $<=2$ млн.евро \\
\hline Малко предприятие & $<50$ & $<=10$ млн.евро & $<=10$ млн.евро \\
\hline Средно предприятие & $<250$ & $<=50$ млн.евро & $<=50$ млн.евро \\
\hline
\end{tabular}

Световната банка също използва три количествени критерия за определяне на МСП: брой служители, общи активи в щатски долари и годишни продажби в щатски долари (IEG: 2008). Бизнесът трябва да отговаря на количествените критерии за броя на служителите и поне един финансов критерий, за да бъде категоризиран като микро, малък или среден бизнес.

Таблица 3. Дефиниция на малките и средни предприятия сьгласно определенията на Световната банка

\begin{tabular}{|l|c|c|c|}
\hline $\begin{array}{c}\text { Категория } \\
\text { предприятие }\end{array}$ & $\begin{array}{c}\text { Брой на } \\
\text { персонала }\end{array}$ & Годишен оборот & $\begin{array}{c}\text { Стойност на } \\
\text { активите }\end{array}$ \\
\hline $\begin{array}{l}\text { Микро } \\
\text { предприятие }\end{array}$ & $<10$ & $<=100000$ щ.д. & $<=100000$ щ.д. \\
\hline $\begin{array}{l}\text { Малко } \\
\text { предприятие }\end{array}$ & $\begin{array}{l}<=50 \\
<0\end{array}$ & $\begin{array}{l}>100000 \text { щ.д. } \\
<=3000000 \text { щ.д. }\end{array}$ & $\begin{array}{l}>100000 \text { щ.д. } \\
<=3000000 \text { щ.Д. }\end{array}$ \\
\hline $\begin{array}{l}\text { Средно } \\
\text { предприятие }\end{array}$ & $\begin{array}{l}>50 \\
<=300\end{array}$ & $\begin{array}{l}>3000000 \text { щ.д. } \\
<=15000000 \text { щ.д. }\end{array}$ & $\begin{array}{l}>3000000 \text { щ.д. } \\
<=15000000 \text { щ.Д. }\end{array}$ \\
\hline
\end{tabular}

Ако сравним двете дефиниции, се наблюдават сравнимост в количествените критерии за броя на служителите, с изключение на това, че Световната банка има по-голям праг за средни предприятия до 300 работници. Несъответствията са най-силно изразени във 
финансовите критерии. Критериите на Световната банка използва значително по-малки прагове от Европейския съюз. Докато за ЕС микро предприятието има оборот до 2 милиона евро, за Световната банка той не трябва да надхвърля годишните продажби до сто хиляди долара. ЕС определя максимален праг от петдесет милиона евро, за да разграничи средния бизнес от големите, докато световната банка го определя само на петнадесет милиона долара за двата финансови критерия.

През 2008 година в цитирания труд на авторите Gibson и Van der Vaart(Gibson и Van der Vaart,2008) предлагат ново определение за МСП, което да бъде универсално, а именно „МСП е компания с годишен оборот между 10 и 1000 пъти средния брутен национален доход в щатски долари на глава от населението, по паритет на покупателната способност на страната, в която той работи.“ Научните среди и политиците все още не са възприели тази алтернативна формула за дефиниране на МСП.

\section{2. Критики на количествените критерии}

Част от авторите по темата смятат, че използването на количествени характеристики като броя на заетите или годишния оборот са мярка за мальк бизнес, но може да не са адекватна мярка или разделител между големите и малки компании. Curran и Blackburn (Curran и Blackburn, 2001) отбелязват, че дефиницията на МСП по брой на заетите лица е станала трудно приложима поради по-голямата употреба на непълно работно време или временна работа от страна на работодателите. Дьлгосрочната заетост като относителен процент все повече намалява, тъй като работниците намират новаторски форми на ангажираност на работното място, не само по отношение на съдържанието, но и по отношение на графиците. Считаме, че към настоящия момент този недостатък е ограничен чрез въвеждане на дефиниция за броя на заетите лица, според които средно списъчен брой на персонала, се изчислява като се отчита часовата заетост спрямо пълен работен ден. Въпреки че броят на служителите представлява обективен и лесно приложим критерий, той има някои ограничения, главно защото броят на заетите зависи от сектора на бизнеса, което прави трудно обобщени сравнения между секторите (Stokes and Wilson, 2010). Според нас това ограничение е съществено във времето на бурното развитие на високотехнологичните компании и развитието на изкуствения интелект, когато човешките ресурси се заменят от машини и технологии.

Авторите работещи по темата, чиито становища и ние подкрепяме, считат че финансовите критерии също имат недостатъци. Сред недостатъците на използването на годишния оборот като определящ фактор при определянето на МСП са приложимите счетоводни стандарти при изготвянето на финансовите отчети, което може да доведе до несравнимост и несъответствия. Инфлацията и валутните курсове правят сравненията във времето и между страните по-трудни (Stokes and Wilson, 2010). За Гибсън и Ван дер Ваарт (2008 г.) критерият за оборота е най-последователният от трите количествени критерия. Критерия за общата сума на баланса, въведена от ЕК е най-критикуваната дефиниция (Hauser 2005, Gibson, Van der Vaart, 2008). Техните основни аргументи са свързани с това, че независимо, че в стойността на баланса са включени всички дълготрайни активи, материалните и нематериалните активи, вземанията и начислените разходи (accrued expenses), не всички икономики прилагат едни и същи принципи. Тези становища се подкрепят и от Международния съвет за счетоводни стандарти (IASB). При разработването на международните стандарти за финансова отчетност (IFRS) IASB предлага качествени критерии за дефиниране на МСП, които критерии да позволят хармонизация и сравнимост на финансовите отчети за МСП, независимо, че в рамките на държавата може да се използват количествени критерии за класификации.

Други автори смятат, че оборотьт заедно със заетите лица не са достатъчни критерии за дефинирането на сектора, и не могат да осигурят сравнимост, защото оборота варира 
значително при икономическите сектори (d'Amboise, 1991 ), поради което е необходим още един критерий, който Hauser (Hauser, 2005) смята че трябва да е типът на икономическата дейност (този критерий се прилага в САЩ и Япония например). За да се компенсира липсата на показател за индустрията, Европейската комисия предлага да се приеме оборота или сумата на баланса. Предложената дефиниция на ЕC не предлага различно третиране на различните икономически сектори (European Commission,2005)..

\section{3. Качествени критерии (характеристики)}

Друга част от авторите, работещи по темата използват дефиниции за МСП, която не включва количествени показатели защитавайки мнението си с твърдението, че „Малките фирми могат трудно да се дефинират чрез точно определение, но повечето са лесни за разпознаване, когато се разгледа тяхната дейност“ (Stokes and Wilson, 2010).

Качествените критерии описват състоянието или мястото на компанията в дадена индустрия. Разгледаните теоретични постановки ни дават основание да заключим, че следните показатели са най-често предмет на изследване, като качествени характеристики:

- Правната независимост на собствениците;

- Значителната роля на собственика в управлението;

- Опростена организационна структура;

- Собствено финансиране;

- Недоминиращо пазарно влияние.

Theile (Theile, 1996) намира две основни разграничения между малките и средните предприятия от големите, и това са "личният принцип" и "единството на лидерството и капитала" (както е цитирано в Loecher, 2000). Според Loecher личният принцип означава, че мениджърът на компанията изпълнява централна роля в процеса на вземане на бизнес решения, защото разбира, че компанията е задължение за цял живот, той поддържа директен контакт със служители, клиенти и доставчици. Принципът на единство на ръководството и капитала означава, че собственикът и управителя на дружеството е едно и също лице, като ръководителят и собственикът в допълнение към ръководните задължения поема всички или поне част от рисковете и отговорностите. Идеята за обединяване на имуществото и управлението, е отразено в критериите на Европейската комисия (EC, 2003), които добавят към количествените критерии и друг критерий, изразен чрез процента на собственост на едно лице, да не е по-мальк от $25 \%$, за да се определи бизнеса като автономен.

Докладът Болтън, като отправна точка за дефинирането на МСП за всяка следваща литература в тази област, определя три основни характеристики на малките фирми: управление на фирмата от нейния собственик; относително мальк дял от пазара; независимост в смисъл, че тя не е част от по-голямо предприятие, относително свободна от външен контрол в основните му решения (Bolton,1971, цитиран в Stokes and Wilson, 2010). Но в същото време докладът на Болтън признава, че слабостта на дефинирането с качествени характеристики, е че е трудно да се анализира секторьт.

Според някой автори управленската структура е основната качествена характеристика, както Питър Дракър пише, „една компания е голяма, колкото нейната управленска структура го изисква“. Организационната структура на малките компании е проста и се отличава с наличието на един център на вземане на решения. МСП се характеризира със специализираната роля на собственика, която го поставя в лидерската позиция в структурата като предприемач и мениджър. Малките и средни предприятия се отличават още и по начина на финансиране - предимно със собствен капитал, а заемите често са предоставени от членове на семейството или от приятели. Тази последна черта играе важна роля, особено при стартиране на бизнеса.

В научната литература се срещат множество класификации на качествените характеристики. Една от интересните класификации е представена от К. Poznanska и 
M.Sculte-Zurhausen.( Poznanska A., Sculte-Zurhausen M.,1994)

\begin{tabular}{|c|c|c|}
\hline \multirow{2}{*}{$\begin{array}{c}\text { Критерии управленски } \\
\text { функции }\end{array}$} & \multicolumn{2}{|c|}{ Размер на компанията } \\
\hline & Малки компании & $\begin{array}{c}\text { Средни и големи } \\
\text { компании }\end{array}$ \\
\hline \multicolumn{3}{|c|}{ Управленска система } \\
\hline Управленски функции & Изпълняват се от собственика & $\begin{array}{c}\text { Изпълняват се от } \\
\text { професионални } \\
\text { мениджъри }\end{array}$ \\
\hline Планиране & Почти не се изпълнява & Критично значение \\
\hline Интуиция за бизнес & Жизненоважна & Незначително \\
\hline $\begin{array}{l}\text { Групово вземане на } \\
\text { решения }\end{array}$ & Практикува се много рядко & практикува се често \\
\hline \multicolumn{3}{|c|}{ Организация } \\
\hline $\begin{array}{l}\text { Организационна } \\
\text { структура }\end{array}$ & $\begin{array}{c}\text { Опростена, доста често } \\
\text { функционална }\end{array}$ & Комплексна \\
\hline $\begin{array}{l}\text { Гъвкавост на } \\
\text { структурата }\end{array}$ & Висока & Ниска \\
\hline Комуникация & Директни контакти & Формализирана система \\
\hline $\begin{array}{l}\text { Формализация на } \\
\text { задачите }\end{array}$ & Ниска степен & Висока \\
\hline Управление на запасите & Базирана на ордери & $\begin{array}{c}\text { Базирана на дългосрочни } \\
\text { договорености }\end{array}$ \\
\hline $\begin{array}{l}\text { Специализация на } \\
\text { задачите }\end{array}$ & Ниска степен & Висока \\
\hline \multicolumn{3}{|c|}{ Доставки и продажби } \\
\hline $\begin{array}{l}\text { Изпълнение на пазарните } \\
\text { нужди }\end{array}$ & Индивидуални нужди & Масово потребление \\
\hline Пазарни позиции & $\begin{array}{c}\text { Различни за различните } \\
\text { компании }\end{array}$ & Добри \\
\hline $\begin{array}{l}\text { Позиция при договаряне } \\
\text { със снабдители }\end{array}$ & Слаба & Силна \\
\hline \multicolumn{3}{|c|}{ Финанси } \\
\hline Собственост на капитала & Собствен/семеен капитал & $\begin{array}{c}\text { В значителна степен от } \\
\text { капиталовите пазари }\end{array}$ \\
\hline $\begin{array}{l}\text { Достъп до капиталовите } \\
\text { пазари }\end{array}$ & Труден & Свободно \\
\hline Разходи за НИРД & Незначителни & Значителни \\
\hline \multicolumn{3}{|c|}{ Персонал } \\
\hline Брой на персонала & Мальк & Голям \\
\hline $\begin{array}{l}\text { Отношения между } \\
\text { персонала }\end{array}$ & Между всички от персонала & Само в работните екипи \\
\hline
\end{tabular}

Източник: Poznanska A., Sculte-Zurhausen M.

Таблица 4 представя някои качествени показатели, определящи МСП, обобщени от UNIDO - „Организацията за индустриално развитие“ на Организацията на обединените нации. 
Таблица 4. Качествени показатели за разпознаване на МСП от големи компании

\begin{tabular}{|c|c|c|}
\hline Категория & МСП & Големи Предприятия \\
\hline Управление & $\begin{array}{c}\text { Функции свързани с личността; } \\
\text { Собственик предприемач }\end{array}$ & $\begin{array}{l}\text { Професионално управление; } \\
\text { Функционално разпределение }\end{array}$ \\
\hline Персонал & $\begin{array}{c}\text { Мултидисциплинарен; } \\
\text { Липса на служители с } \\
\text { университетско образование }\end{array}$ & $\begin{array}{c}\text { Доминиране на служители с } \\
\text { университетско образование; } \\
\text { Специализация } \\
\end{array}$ \\
\hline Организация & Персонални контакти & Формализирана комуникация \\
\hline Продажби & Несигурни & Силна конкурентна позиция \\
\hline $\begin{array}{l}\text { Отношения с } \\
\text { клиенти }\end{array}$ & Нестабилни & $\begin{array}{c}\text { Базирани на дългосрочни } \\
\text { контакти } \\
\end{array}$ \\
\hline Производство & Интензивно на труд & $\begin{array}{c}\text { Интензивно на капитал; } \\
\text { Икономии от мащаба }\end{array}$ \\
\hline НИРД & $\begin{array}{c}\text { Следват пазара; } \\
\text { Интуитивен подход }\end{array}$ & Институционализирани \\
\hline Финанси & $\begin{array}{l}\text { Самофинансиране; } \\
\text { Семейни финанси }\end{array}$ & $\begin{array}{c}\text { Диверсифицирана капиталова } \\
\text { структура; } \\
\text { Достьп до капиталови пазари }\end{array}$ \\
\hline
\end{tabular}

Източник: UNIDO (цитирано от Yon and Evans, 2011)

Друг учен, Marwede също предпочита дефинициите на МСП, основаващи се на качествени аспекти, като например правната форма, ролята на собственика на фирмата, позицията на фирмата на пазара, организационната структура или икономическата и юридическата автономия (цитиран в Decker et al., 2006)

Подкрепа на авторите защитаващи прилагането на качествените характеристики предлагат и Ferreira и Leite (Ferreira и Leite, 2011), като отбелязват, че няколко проучвания са показали, че въпреки несъответствията в количествените критерии МСП в различните страни, техните организационни, културни и стратегически характеристики са сходни. „Тези аспекти са качествени, но въпреки това предоставят основание за създаване на по-широка хомогенна гледна точка в анализа на фирмите по света““(Ferreira и Leite, 2011).

Van Hoorn (Van Hoorn, 1979) (по Brooksbank, 1991) предлага пет характеристики, които разграничават по-малките от по-големите фирми:

- Сравнително ограничен брой на продукти, технологии и ноу-хау;

- Сравнително ограничени ресурси и възможности;

- По-слабо развита система за управление, административни процедури и техники;

- Несистематичен и неформален стил на управление;

- Ръководните длъжности се изпълняват от учредителите на фирмата и/или техните роднини.

Според Storey $($ Storey, 1994) има три ключови области, по които малките фирми са различават от големите фирми, това са - несигурност, иновации и еволюция.

Първата ключова област, която отличава малките от големите фирми е несигурността, която се дефинира в три измерения:

○ Малките фирми имат незначителен пазарен дял и не могат да влияят на пазарните цени, поради което приемат цените наложени от пазара;

○ Клиентите и продуктовата им гама обикновено са ограничени и по-често малките 
фирми действат като подизпълнители на по-големите, поради което са по-уязвими в сравнение с доминиращите големи фирми;

○ Целите, които си поставят собствениците на малките фирми са много поразнообразни, в сравнение с целите на големите компании. Собствениците на малкия бизнес нямат задължения за отчитане пред външни акционери и затова мониторинга на резултатите реално не съществува. В малката фирма собствеността и контролът са в ръцете на един или няколко души, често пъти на един собственик, който е и управител и не съществуват проблемите между собствениците и мениджмънта.

Ролята в иновациите е втората ключова област. Малките фирми често играят „нишова роля“", те добавят нещо значително в характеристиките на продуктите или услугата, което ги отличава от по-стандартизирания продукт или услуга на големите фирми. Малката фирма е много по-малко вероятно да предприеме изследвания и разработки, отколкото по-голямата фирми и е по-малко вероятно да отделя персонал, който се занимава изключително с научни изследвания. Но въпреки това е по-вероятно е малките фирми да въведат фундаментално нови продукти, отколкото по-големите. Малките фирми са по-малко ангажирани със съществуващите продукти.

Третата ключова област е много по-голямата вероятност за развитие и промяна в помалката фирма. Малките фирми претърпяват редица етапни промени, които влияят върху ролята, стила на управление и структурата на организацията. По-вероятно е структурата и организацията на малката фирма да претьрпи голяма промяна докато фирмата преминава от един етап в друг, отколкото е при по-големите фирми.

\section{4. Критики на дефинирането с качествени характеристики}

Основните критики към дефинирането на МСП чрез използването на качествени характеристики са свързани с трудността за събиране и обобщаване на данни за статистическата отчетност, както и извършването на анализи.

\section{Заключение}

Разглеждайки определенията за МСП, при които се прилагат основно количествените характеристики и то най-вече броя на заетите лица, може да се стигне до извода, че се дискриминират част от предприятията, които имат характер на МСП, но имат например 255 служители. Дали тези 5 служители могат да променят характера на предприятието? В тази връзка ние считаме, че при дефинирането на малките и средните предприятия трябва освен количествените критерии трябва да се включат и качествени характеристики.

Чрез настоящия труд предлагаме следното определение на МСП - „Независимо предприятие, чиито собственик играе основна роля в управлението, с недоминиращо пазарно влияние и годишен оборот до 500 пъти средния брутен национален доход на глава от населението, по паритет на покупателната способност в страната, в която оперира.

\section{References}

1. Annual Report on European SMEs 2017/2018, https://ec.europa.eu/growth/content/europeancharter-small-enterprises-0_en, European chart for Small Enterprises, published on 20.06.2000

2. Ayyagari,M., Beck T and Deirguc-Kunt, (2007) "A Small and Medium Enterprices across the Globe", Springelink December, Volume 29, Issue 4, pp 415-434

3. Beck, T. \& Cull, R. (2014). "Small and medium-sized enterprise finance in Africa" African Growth Initiative (working paper 16). Washington DC: Brookings.

4. Brooksbank, R., (1991), "Defining the small business: a new classification of company size

5. Costica Buculescu,M. (2013) "Harmonisation process in defining small and medium sized enterpeises. Arguments for quantitive versus a qualitive one", Theoritical and Applied 
Economics, Volume XX (2013) No 9 (586) pp 103-114, Bucurest University of Economic Studies

6. Curran,J.\&Blackburn,RA, (2001) "Researching the small enterprise" London, SAGE Publications

7. Decker,M,Schiefer,G,Bulander,R (2006) "Specific chalanges for small and medium sized Enterprises (SMEes) in $\mathrm{m}$-business" , Filipe, J Greene, T (Publisher): Proceedings of the international conference on e-business. Setubal:INSTICC Press pp 169-174

8. D'Amboise, G. (1991). "The Canadian Small and Medium sized enterprise: Situation and Challenges", The Institute for Research on Public Policy

9. Dalberg. (2011). "Report on support to SMEs in developing countries through financial intermediaries". Washington, D.C.: Dalberg

10. European Commission (2003). "Recommendation 2003/361/EC: SME Definition"

11. Filion, L.J. (1990). "Free trade: The need for a definition of small business", Journal of Small Business and Entrepreneurship, Vol. 7, No. 2, Jan-March, pp. 33-46

12. Ganguly, P. (1985). "UK. Small Business Statistics and International Comparisons", Canada's Small Business Data Centre, GDSourcing

13. Gibson, T., van der Vart, H.J. (2008). "Defining SMEs: A less imperfect way of defining Small and Medium Enterprises in Developing Countries", Brookings Global Economy and Development, September

14. Independent evaluation group Financing micro,small and medium Enterprises, An independent Evaluation of IFC's experience with Financial intermediars in frontier Countries" http://ieg.worldbankgroup.org/evaluations/small-enterprises,

15. Kushnir,Mirmulstain, ML,Ramalho,R,Micro (2010), "Small and medium enterprises araund the world how many are there, and what affects the count?,MSME Country indicators. World Bank ,IFC

16. Leite, MP, Ferreira, A.(2011) "SMEs and e-Business: Implementation, Strategies and Policy.Ebusiness managerial Aspects: solutions and case studies" (Ed. Cruz-Cunha and Varajâo).Business Science Reference.IGI Global, pp 1-22

17. Loecher, (2000) "Small and medium -sized enterprises: delimination and the European definition in the area od the industrial business", European Business review,2000, 12,(5), 261-264

18. OECD, (2010). SMEs, "Enterpreneurship and innovation”, Paris Osteryoung, J.S. and Newman, D. (1993). "What is a Small Business?", The Journal of Small Business Finance, 2(3), pp 219231

19. Osteryoung, J.S. and Newman, D. (1993). "What is a Small Business?", The Journal of Small Business Finance, 2(3), pp 219-231

20. Poznanska A.,Sculte-Zurhausen M., (1994) "Kryteria klasyfikacji matych i srednich przedsiebirstw ", Przeglad Organizacji", p.26

21. Stokes, D.,Wilson,N (2010) "Enterpreneurship and small Business management" (6 th ed), Cengage Learning EMEA,

22. Stokes,J,Wilson. N, (2010) "Small Business Management and Entrepreneurship", Cengage Learning EMEA, 2010

23. Storey, D. J., (1994), Understanding the Small Business Sector, Thomson

24. Yon, R,Evans,D (2011) “The role of small and medium enterprices in Frontier capital markets", Network Science Center, West Point

25. Varimezov, Lubcho,(2000) “Malkite kompanii v savremennata ikonomika”, Stopanska akademia „D.A Cenov“, Svishtov

26. Rakovodstvo za potrbitelia otnosno definiciata za MSP”, 2017 https://publications.europa.eu/bg/publication-detail/-/publication/79c0ce87-f4dc-11e6-8a3501aa75ed71a1 